\title{
Himawari-8 infrared observations of the June-August 2015 Mt Raung eruption, Indonesia
}

\author{
Takayuki Kaneko $^{1 *} \mathbb{D}$, Kenji Takasaki ${ }^{2}$, Fukashi Maeno ${ }^{1}$, Martin J. Wooster ${ }^{3}$ and Atsushi Yasuda ${ }^{1}$
}

\begin{abstract}
Volcanic activity involves processes that can change over short periods of time, which are sometimes closely related to the eruptive mode or the timing of its transitions. Eruptions bring high-temperature magma or gas to the surface; thermal observations of these eruptions can be used to determine the timeline of eruptive sequences or eruptive processes. In 2014, a new-generation meteorological satellite, Himawari-8, which carried a new sensor, the Advanced Himawari Imager (AHI), was launched. The AHI makes high-frequency infrared observations at a spatial resolution of $2 \mathrm{~km}$ during 10-min observation cycles. We analyzed an effusive eruption that occurred in 2015 at Mt Raung in Indonesia using these AHI images, which was the first attempt applying them to volcanological study. Based on the detailed analysis of the time-series variations in its thermal anomalies, this eruptive sequence was segmented into a Precursory Stage, Pulse 1, Pulse 2 and a Terminal Stage. Pulses 1 and 2 are effusive stages that exhibited a consecutive two-pulse pattern in their variations, reflecting changes in the lava effusion rate; the other stages are non-effusive. We were also able to determine the exact times of the onset and reactivation of lava flow effusion, as well as the precursory signals that preceded these events.
\end{abstract}

Keywords: Himawari-8, Volcano, Eruption, Remote sensing, Thermal anomaly, Indonesia, Raung

\section{Introduction}

Volcanic activity includes processes that can change over short periods of time, such as explosions, the activation of fumarole emissions related to the ascent of lava or the opening of an effusive vent. These processes are sometimes closely related to eruptive modes or states or the timing of their transitions. Therefore, observations of short-term phenomena as well as those of long-term variations are important for the analysis of eruptive sequences (Oppenheimer et al. 1993; Wooster and Rothery 1997). Eruptions are basically phenomena that emit high-temperature materials, such as magma or gas, onto the surface; thus, the use of high-frequency infrared observations, which can detect the ejection of these materials as high-density time-series variations in

\footnotetext{
*Correspondence: kaneko@eri.u-tokyo.ac.jp

1 Earthquake Research Institute, The University of Tokyo, 1-1-1 Yayoi,

Bunkyo-Ku, Tokyo 113-0032, Japan

Full list of author information is available at the end of the article
}

thermal anomalies, is an effective approach for analyzing eruptive modes or states and eventually characterizing eruptive sequences.

Satellite remote sensing has been widely applied to obtain thermal observations of active volcanoes (Francis and Rothery 1987; Rothery et al. 1988; Oppenheimer 1997; Harris 2013). However, high-temporal-resolution images that can capture short-term eruptive phenomena were not available until recently. In 2014, a new-generation meteorological satellite, Himawari-8, which carried a newly developed sensor, the Advanced Himawari Imager (AHI), was launched and entered service in July 2015 (Japan Meteorological Agency 2015a). This instrument enabled the collection of very high-frequency thermal observations that had never before been obtained.

Himawari-8 operates at a geostationary position located approximately $35,800 \mathrm{~km}$ above the equator at $140.7^{\circ} \mathrm{E}$. The AHI instrument operates in 16 wave bands from the visible to thermal infrared regions, with a spatial resolution of $0.5-1 \mathrm{~km}$ for the visible to near-infrared 
bands and $2 \mathrm{~km}$ for the shortwave to thermal infrared bands; it also captures full-disk images every $10 \mathrm{~min}$ (Japan Meteorological Agency 2015a).

This study analyzes the effusive eruption involving Strombolian and/or lava fountaining that occurred in Mt Raung from June to August 2015 (hereafter referred to as the "June-August 2015 Mt Raung eruption") using the Himawari-8 AHI images and examined its eruptive sequence based on the combination of short- and longterm variations in thermal anomalies, which is the first attempt applying Himawari-8 AHI images to characterizing eruptive activities. Mt Raung, which is one of the most active volcanoes in Indonesia, is located in the easternmost part of Java (Fig. 1a) (Neumann van Padang 1951; Newhall and Dzurisin 1988; Global Volcanism Program 2015). Mt Raung has a large conical edifice with a height of $3260 \mathrm{~m}$ above sea level as well as a summit caldera that is approximately $2 \mathrm{~km}$ in diameter (Figs. $1 \mathrm{~b}$ and $2 \mathrm{a}, \mathrm{c}$ ). There is an intra-caldera cone in the floor, which is where the June-August 2015 eruption occurred. Although this Mt Raung eruption was one of the largest effusive eruptions that occurred in East Asia in 2015, the details were unknown prior to this study. It has been an important issue to know how effusion rate changes both in long and short term during effusive activity. Highfrequency infrared observations by Himawari- 8 are expected to give new findings to consider this issue.

\section{Data and methods}

\section{Himawari-8 AHI imaging}

In this study, we use the shortwave to thermal infrared bands of the AHI (i.e., 1.6, 2.3, 3.9 and $11 \mu \mathrm{m}$; with a spatial resolution of $2 \mathrm{~km}$ ) for observations. The AHI data were received at the Meteorological Satellite Center of the Japan Meteorological Agency and were transferred to distribution servers at several institutes. We downloaded the full-disk data of the AHI between June and August 2015 from the NICT Science Cloud of the National Institute of Information and Communication Technology (Website: http://sc-web.nict.go.jp/himawari/). Radiometric corrections were applied to the downloaded AHI data using the correction coefficients given in each header (Japan Meteorological Agency 2015b), and the $101 \times 101$-pixel areas that exhibited Mt Raung in their centers were extracted based on the geometric relationship defined by the normalized geostationary projection (Coordination Group for Meteorological Satellite 1999); these areas were then used for further analysis.

\section{Observation of thermal anomalies using infrared images}

When measuring a volcanic hot spot from space, the

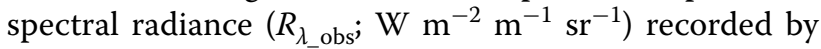
the satellite is described as follows:

$$
R_{\lambda \_ \text {obs }}=\varepsilon_{\lambda} \tau_{\lambda} R_{\lambda}+R_{\lambda}^{\uparrow}+\tau_{\lambda}\left(1-\varepsilon_{\lambda}\right) R_{\lambda}^{\downarrow}+\tau_{\lambda} R_{\lambda \_ \text {ref }}
$$

where $\lambda$ is the wavelength $(\mathrm{m}), R_{\lambda}$ is the spectral radiance from a black-body at the surface, $R_{\lambda}^{\uparrow}$ is the upwelling atmospheric radiance, $R_{\lambda}^{\downarrow}$ is the downwelling atmospheric radiance, and $R_{\lambda \text { ref }}$ is the sunlight reflected by the surface. Additionally, $\varepsilon_{\lambda}$ is the emissivity of the radiating surface and $\tau_{\lambda}$ is the atmospheric transmittance. The first term on the right-hand side is the thermal radiation that is emitted from the surface. The third term is the component of the downwelling atmospheric radiance that is reflected by the surface. $R_{\lambda}$, which is emitted from the surface at a temperature $T(K)$, is given by the Planck equation, which is defined as follows:

$$
R_{\lambda}=\frac{C_{1} \lambda^{-5}}{\pi\left[\exp \left(\frac{C_{2}}{\lambda T}\right)-1\right]}
$$

where $C_{1}=3.742 \times 10^{-16} \mathrm{~W} \mathrm{~m}^{2}=2 \pi h c^{2}$ (where $h$ is Planck's constant and $c$ is the speed of light) and $C_{2}$ $=0.0144 \mathrm{~m} \mathrm{~K}=h c / k$ (where $k$ is Boltzmann's constant).

Here, when we use nighttime data, the fourth term on the right-hand side of Eq. (1) can be ignored and the second and third terms are negligible in these wavelengths except for $R_{\lambda}^{\uparrow}$ for the $11 \mu \mathrm{m}$ band. At Mt Raung, this value was estimated to be $0.269 \times 10^{6} \mathrm{~W} \mathrm{~m}^{-2} \mathrm{~m}^{-1} \mathrm{sr}^{-1}$ using the MODTRAN radiative transfer code obtained under tropi$\mathrm{cal}$ atmospheric conditions at a height of $2900 \mathrm{~m}$. The values of atmospheric transmittance $\left(\tau_{\lambda}\right)$ were also estimated to be $0.95,0.92,0.92$ and 0.95 for the 1.6, 2.3, 3.9 and $11 \mu \mathrm{m}$ bands, respectively, by the same software. The emissivity $\left(\varepsilon_{\lambda}\right)$ value was assumed to be 0.95 for all bands. The values of $R_{\lambda}$ (=atmospherically and emissivity corrected radiance; Harris 2013) were obtained using the following equation, which was used for the analysis of thermal variations:

$$
R_{\lambda}=\left(R_{\lambda \_\mathrm{obs}}-R_{\lambda}^{\uparrow}\right) / \tau_{\lambda} \varepsilon_{\lambda}
$$

\section{Observation of effusive eruptions using nighttime $\mathrm{AHI}$ $1.6 \mu \mathrm{m}$ images}

Here, we assume that the area covered by the erupted lava is always included in an AHI pixel area (approximately $2 \times 2 \mathrm{~km}$ ). In this case, at least two temperatures are found on the surface within a pixel; these temperatures correspond to the ground surface (i.e., the background temperature) and the effused lava surface (i.e., high-temperature regions). As shown in Fig. 3, the highly nonlinear $1.6 \mu \mathrm{m}$ curve, with increasing steepness at high temperature, indicates that the $1.6 \mu \mathrm{m}$ wave band preferentially reflects thermal anomalies derived from areas with high 
temperatures, such as those of more than several hundred degrees $C$, even if these areas account for only small portions of the surface within the pixel (Wooster and Rothery 1997). The 2.3 and $3.9 \mu \mathrm{m}$ bands are also likely to be dominated by radiation from the high-temperature surfaces, but surfaces at the lower temperature than that will also emit considerably within these wave bands. For the 11 $\mu \mathrm{m}$ band, the relationship between these two parameters is nearly linear (Fig. 3); thus, the radiance mainly reflects the temperature of the area occupying the largest portion within the AHI pixel, which is usually the background.

Assuming that the temperature of the magma and the thickness of the effusing lava are constant throughout the duration of the effusive activity, higher effusion rates will cause the size of the high-temperature area to increase, thus producing a higher signal related to the thermal anomalies in the $1.6 \mu \mathrm{m}$ images. High-temperature regions on the surface are believed to cool down quickly due to the occurrence of effective radiative heat loss from the surface following effusion (Dragoni 1989; Ishihara et al. 1990; Oppenheimer 1991). A simplified estimate indicates that the surface of a lava flow with a temperature of $1100{ }^{\circ} \mathrm{C}$ can drop to a temperature of $350{ }^{\circ} \mathrm{C}$ in $3 \mathrm{~h}$ through radiative cooling (Yamashita and Miyamoto 2009). This suggests that the high-temperature

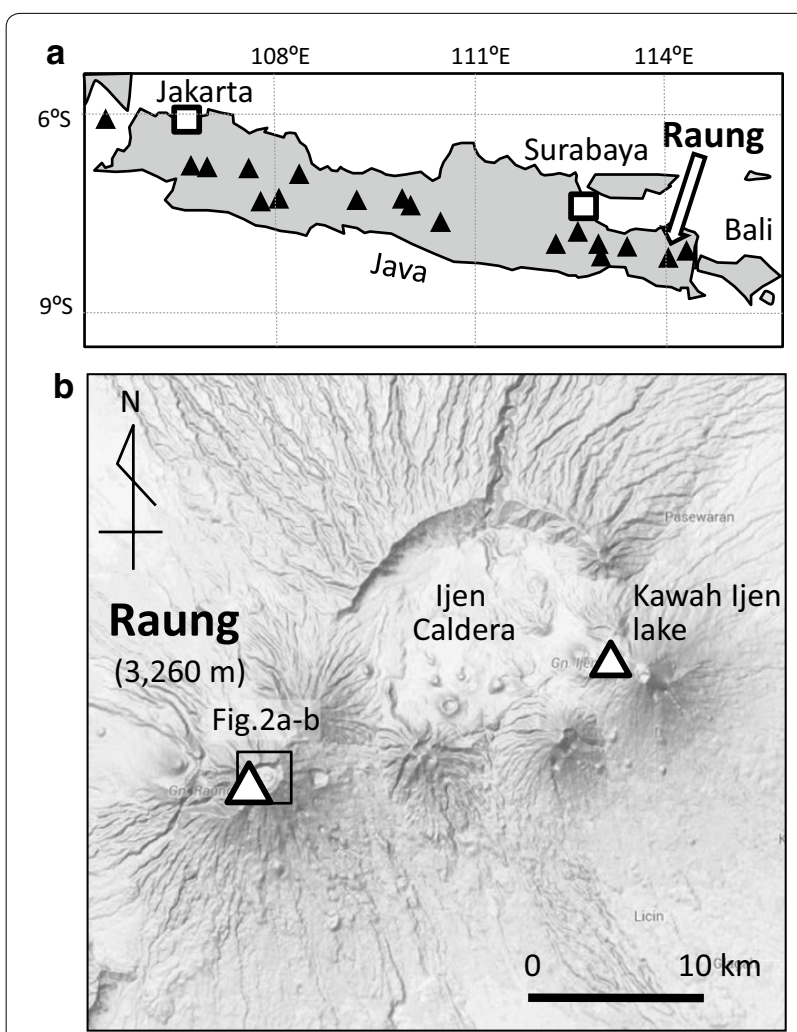

Fig. 1 a Location of Mt Raung. b Mt Raung and adjacent topography. (Reproduced from Google Maps) region occupies a small area within the AHI pixel (i.e., it is limited to the areas neighboring the effusing vent) and that changes in the effusion rate of lava are expected to be effectively reflected in the size of the high-temperature region on the surface and thus as thermal anomalies in the $1.6 \mu \mathrm{m}$ band. In fact, observations obtained using an Along Track Scanning Radiometer (ATSR) exhibited a positive correlation between the thermal radiance recorded by the $1.6 \mu \mathrm{m}$ band data (with a pixel size of $1 \times 1 \mathrm{~km}$ ) and the effusion rate of lava during the period of effusive activity at Unzen between 1991 and 1995 (Wooster and Kaneko 1998).

\section{Indexes used for observation}

In this study, we adopted the following indexes to examine the time-series variations in the thermal anomalies for each band. The calculations of these thermal anomalies were performed by examining a $7 \times 7$ pixel region exhibiting the summit of Mt Raung at its center.

$\mathbf{R 1 . 6 M x}$ and R2.3Mx are the pixel values that exhibit the maximum spectral radiance values in the $7 \times 7$ pixel region in the 1.6 and $2.3 \mu \mathrm{m}$ images, respectively.

T3.9Mx and T11Mx are the pixel values that exhibit the maximum pixel-integrated temperatures in the $7 \times 7$ pixel region in the 3.9 and $11 \mu \mathrm{m}$ images, respectively.

\section{Outline of the June-August 2015 eruption}

The number of volcanic tremors at Mt Raung began to increase on 21 June 2015, and a volcanic glow was observed on 25 and 28 June (Global Volcanism Program 2015). According to the above website, the Badan Nasional Penanggulangan Bencana (BNPB) reported that this increased activity on 28 June was characterized by Strombolian activity. In response to this activity, the Pusat Vulkanologi dan Mitigasi Bencana Geologi (PVMBG) raised the alert level to 3 from 2 (on a scale of 1-4) on 29 June. Nighttime video footage taken by a climber on 1 July (Yanto 2015) showed a Strombolian and/or lava fountain erupting at the top of the intra-caldera cone and a continuous lava flow emanating from its base. Photographs taken from the caldera rim on 14 and 15 August (Pfeiffer 2015) showed that the caldera floor was fully buried by a lava bed and that only small-scale explosive eruptions continued to occur at the summit of the cone. The alert level was lowered to 2 from 3 on 24 August.

Figure 2a shows high-resolution satellite imagery of the caldera taken on 16 June 2015, immediately prior to the beginning of lava effusion. Figure $2 b$ shows the region on 23 August, after volcanic activity ceased. These images demonstrate that the June-August 2015 Mt Raung eruption buried large areas of the caldera floor under a lava bed (Fig. 2c, d). Topographically, this lava bed appears to 

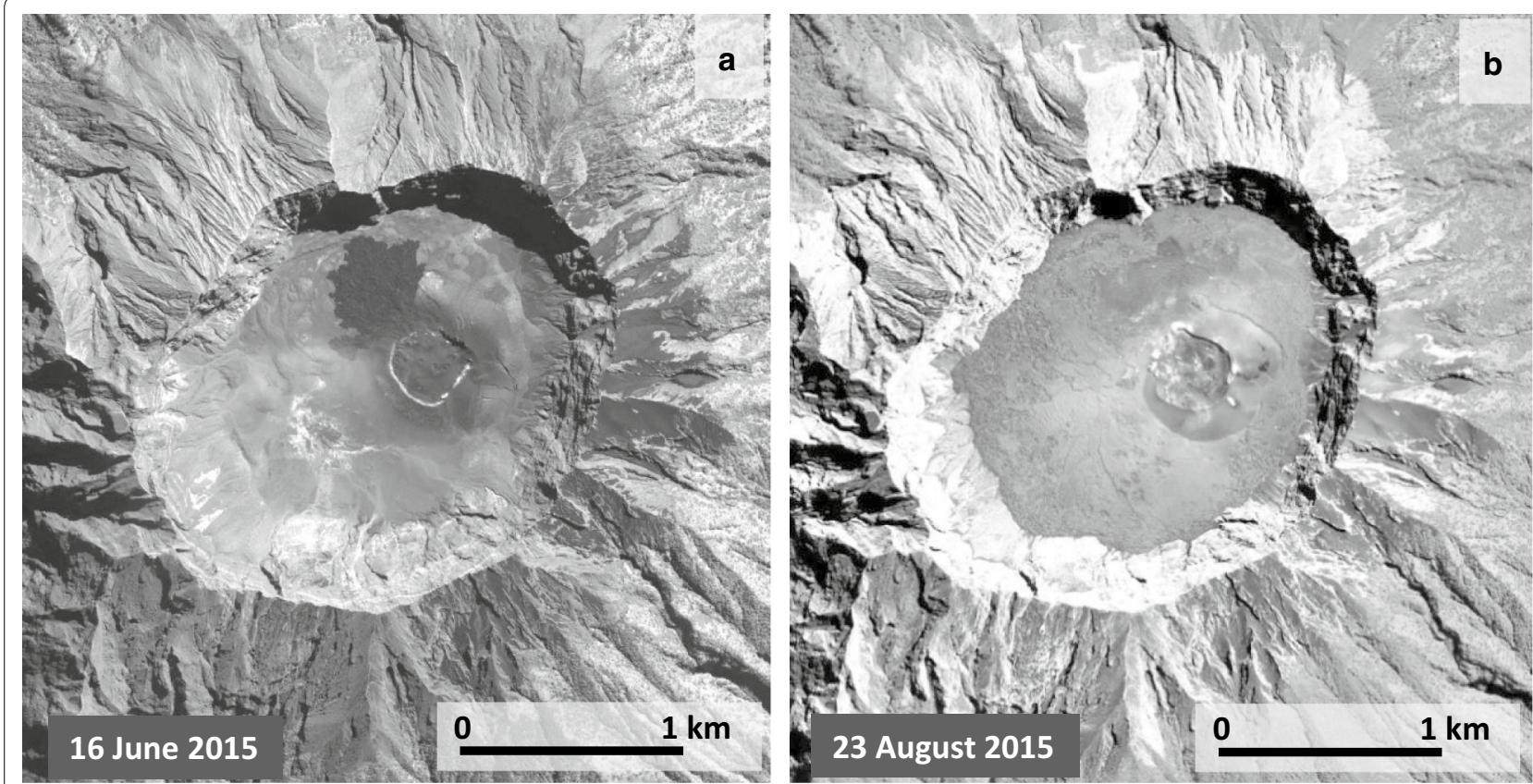

\section{lava flow}

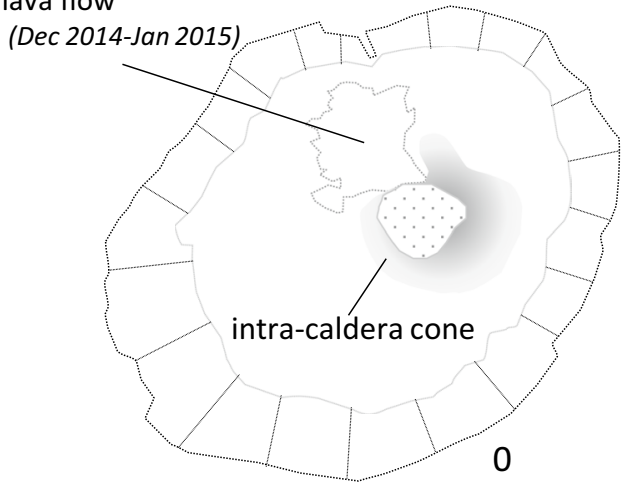

C

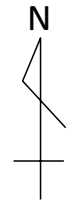

$1 \mathrm{~km}$

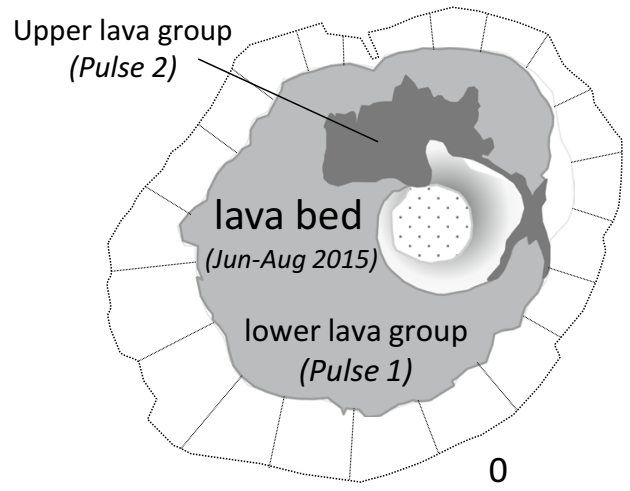

d

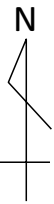

$1 \mathrm{~km}$

Fig. 2 a High-resolution image of the summit caldera before lava effusion taken on 16 June 2015 by WorldView-2 (DigitalGlobe). b High-resolution image of the summit caldera after the eruption taken on 23 August 2015 by WorldView-2 (DigitalGlobe). c Sketch map based on the image collected on 16 June 2015. d Sketch map based on the image collected on 23 August 2015

comprise a lower lava group, which forms the majority of the effused lava, and an upper lava group, which spreads to the northern side of the caldera and overlies the lower lava group (Fig. 2d).

\section{Results}

\section{Long-term variations in thermal data and stage segmentation of activity}

Long-term plots of eruptive activity constructed using 6177 nighttime AHI images acquired between 1 June and 31 August are shown in Fig. $4 a-c$. Although most of the images examined here had no cloud over the volcano (June to August is in the middle of the dry season of Java), a few minor cloudy periods, suggested by low T11Mx values being below the background level, can be recognized (Fig. 4c). Here, we identify long-term variations in this eruptive activity by focusing on the maximum values measured during each day in order to minimize or avoid the influence of the plume or the subpixel size clouds located over the eruptive center, as well as cases where the eruptive center is located on the boundary between two pixels (or occasionally four pixels).

This period of eruptive activity was divided into four stages based on this time-series analysis (Fig. 4d). Two major pulses were recognized in this pattern; the first pulse occurred from 20 June to 1 August (Pulse 1) and the second pulse occurred from 1 to 13 August (Pulse 2). Based on their trends, both pulses were subdivided into 
the Increasing, Peak and Decreasing Periods. Furthermore, in R2.3Mx (Fig. 4b), a low-level thermal anomaly was observed from 14 to 19 June (Precursory Stage), which occurred prior to the start of Pulse 1, and another low-level thermal anomaly was observed from 14 to 20 August (Terminal Stage), which occurred immediately after the end of Pulse 2.

In R1.6Mx, Pulses 1 and 2 exhibited uniformly higher levels of thermal anomalies than the Precursory and Terminal stages; during the latter stages, their levels remained at background values. This indicates that Pulses 1 and 2 were caused by the introduction of a persistent high-temperature heat source, as is suggested by the relationship shown in Fig. 3; thus, these pulses are interpreted to have resulted from the lava that represents the main product of this activity. The effusion rate of lava is believed to have changed to exhibit a consecutive twopulse pattern (Fig. 4e), as is suggested by the variations in its thermal anomalies. Thus, the formations of the lower and upper lava groups of the lava bed (Fig. 2d) most likely correspond to these two pulses.

We assume that the thermal anomaly at $1.6 \mu \mathrm{m}$ basically reflects variations in the effusion rate of lava. This is consistent with the results of seismic observations reported by the Pusat Vulkanologi dan Mitigasi Bencana Geologi (2016), which are based on real-time seismic amplitude measurement (RSAM) data (Fig. 4g). The RSAM counts are believed to be related to the transport of magma to the surface (Endo and Murray 1991). The RSAM counts here exhibit a consecutive two-pulse pattern that is similar to the variations observed in $\mathrm{R} 1.6 \mathrm{Mx}$ (Fig. 4a). The good agreement between these two types of observations supports the supposition presented above.

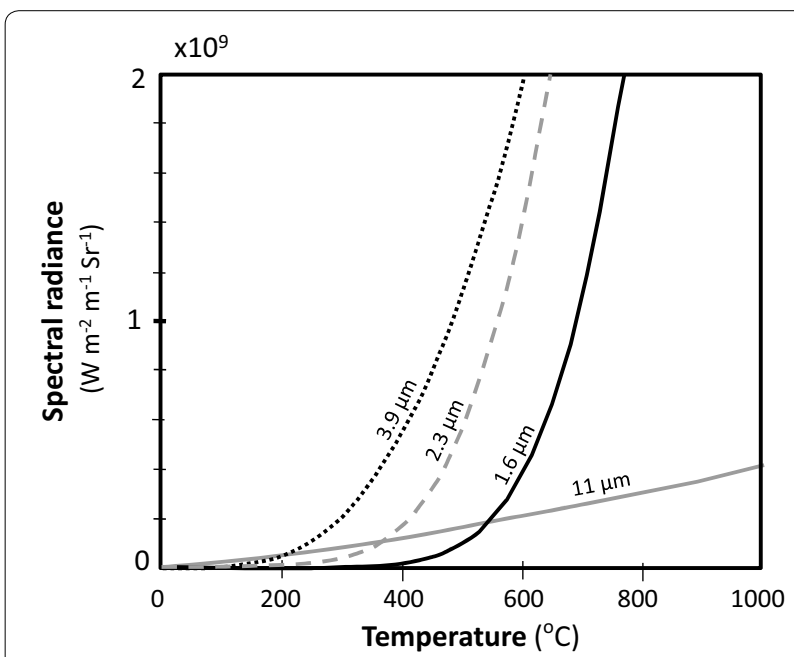

Fig. 3 Relationship between temperature and spectral radiance at different wavelengths based on the Planck equation

\section{Variations during each stage}

Here we describe the variations and characteristics of each stage based on the combined analysis performed using both long- and short-term variations.

\section{Precursory stage/14-19 June ( 6 days)}

In R2.3Mx (Fig. 4b), a low-level thermal anomaly was recorded from 14 to 19 June. During this period, no distinct activity, such as lava effusion or ash emission, was reported. Prior to magma effusion, magma may have risen to a shallow level in the conduit and released hot gas, or heated the surrounding groundwater, which may have caused this slightly increased thermal anomaly, as was observed before previous eruptions, such as the 1986 Izu-Oshima (Kagiyama and Tsuji 1987), 1999 Shishaldin (Dehn et al. 2002) and 2004 Mt Asama (Kaneko et al. 2006) eruptions. This thermal anomaly can thus be interpreted to represent a precursor to the major eruptive phase, which occurred during Pulse 1.

\section{Pulse $1 / 20$ June- 1 August (43 days)}

Pulse 1-increasing period/20-28 June (9 days) On 20 June, the levels of thermal anomalies in $\mathrm{R} 1.6 \mathrm{Mx}, \mathrm{R} 2.3 \mathrm{Mx}$ and $\mathrm{T} 3.9 \mathrm{Mx}$ rose discontinuously from low or background levels and then increased gradually until 28 June (Fig. 4a-c). This gradual increase is interpreted to reflect an increase in the rate of lava effusion.

The time of the onset of lava effusion was not identified using ground-based observations. Figure 5a shows the short-term variations in thermal anomalies from 18 to 20 June using both daytime and nighttime data. During the daytime, each index exhibited an arch-shaped pattern reflecting the reflected sun light from 18 to 19 June. On 20 June, the patterns of R1.6Mx and R2.3Mx were the same as they had been on the previous two days, but that of T3.9Mx where the effect of the reflected sunlight was relatively small, began to increase from the middle of the day at approximately 6:50 UTC (13:50 local time), thus reflecting the start of lava effusion. The effusion continued thereafter, as observed in the nighttime of the same day.

Pulse 1-peak period/29 June-24 July (26 days) High levels of thermal anomalies, including those in $\mathrm{R} 1.6 \mathrm{Mx}$, were continuously recorded from 29 June to 24 July (Fig. 4a-c). This suggests that high levels of lava effusion continued, which likely formed the majority of the lava bed (Fig. 2b, d). Long-term minor fluctuations in these variations are believed to reflect long-term fluctuations in the effusion rate of this lava. In the short-term plots, indexes of thermal anomalies were constant and nearly flat, which suggests that the effusion of lava was stationary (e.g., the nighttime of 20 June in Fig. 5a). 
Pulse 1-decreasing period/25 July-1 August (8 days) Between 25 July and 1 August, the levels of these indexes decreased and finally reached very low levels, which suggests that the effusion rate of lava also decreased to a low level (Fig. $4 \mathrm{a}-\mathrm{c}$ ). During the last day of this stage (1 August), a small thermal pulse occurred several hours before the start of Pulse 2 (Fig. 5b), which can be interpreted to represent a precursory event to the start of Pulse 2 (a small explosive event?).

\section{Pulse 2/1-13 August ( 12 days)}

Pulse 2-increasing period/1-2 August ( 1 day) The thermal anomaly rapidly increased on 1 August (Fig. $4 \mathrm{a}-\mathrm{c}$ ). On the short-term plot (Fig. 5b), this rapid increase started at 20:20 UTC and continued until approximately 14:00-15:00 UTC on the next day.

Pulse 2-peak period/2-3 August ( 2 days) After reaching a climax at approximately 15:00-16:00 UTC on 2 August (Fig. 5b), the anomalies in $\mathrm{R} 1.6 \mathrm{Mx}, \mathrm{R} 2.3 \mathrm{Mx}$ and T3.9Mx quickly began to decrease, such that the Increasing and Peak Periods of Pulse 2 were shorter than those of Pulse 1 (Fig. $4 \mathrm{a}-\mathrm{c}$ ).

Pulse 2-decreasing period/4-13 August (10 days) The Decreasing Period of Pulse 2 continued for 10 days. The upper line of the hatched region during the middle of this period shows the interpolated level during the small depression that was caused by cloud cover (Fig. $4 a-c$ ). During the last few days of this period, these indexes decreased to low levels and finally discontinuously dropped on 14 August, which marks the point when the effusion of lava finally ceased.

\section{Terminal stage/14-20 August (7 days)}

This stage was characterized by a low-level thermal anomaly that was only clearly visible on R2.3Mx (Fig. 4b). As lava effusion cannot be recognized in the photographs taken on 14 and 15 August (Pfeiffer 2015), this thermal anomaly likely reflected the small-scale gas emissions at the cone, from which repeated small-scale eruptions occurred. Finally, the anomaly in $\mathrm{R} 2.3 \mathrm{Mx}$ decreased to its background levels on 21 August, which signaled the end of the June-August 2015 Mt Raung activity.

\section{Discussion}

\section{Characteristics of effusive eruptions of lava based on comparisons with similar activity}

Effusive activity similar to that which occurred at Mt Raung was observed in the 2013-2015 Nishinoshima eruption (Maeno et al. 2016, 2017). During this activity, the long-term variation in the effusion rate of lava gradually increased during the initial stage, remained high for more than 1 year (with some fluctuations), and finally gradually decreased to zero. On shorter timescales, this lava effusion appeared constant in collected video footage (NHK 2015).

Some similarities can be observed between the activity at Nishinoshima 2013-2015 and that at Mt Raung-particularly Pulse 1 . In both cases, the long-term trends of effusion rates of lava were not constant throughout the effusive stages but instead varied, exhibiting a pattern of an initial phase featuring a gradual increase, a middle phase featuring a high level of activity with depressions or fluctuations, and a late phase featuring a gradual decrease. Additionally, on shorter timescales, this rate was basically continuous and changed very gradually. These points may thus represent one of the representative eruptive sequences found in effusive eruptions involving Strombolian and/or lava fountaining.

\section{Application of high-frequency infrared observations to disaster mitigation}

During the June-August 2015 Mt Raung eruption, alert levels were issued by local authorities (Fig. 4f), and changes in these levels appeared to lag behind actual changes in activity, such as the start of lava effusion. One of the reasons for this lag was the difficulty associated with making continuous observations of the caldera floor, which is located at a high altitude. Delays in issuing changes in the alert level may result in disasters for hikers or people residing in the vicinity of the volcano. If we can quickly access information about the state of activity obtained from high-frequency observations using the Himawari-8 AHI, we might be able to minimalize these delays and issue alert levels with appropriate timing. Currently, in our prototype system, we can check the images of targeted volcanoes within $2 \mathrm{~h}$ after scanning of the full disk has been done by Himawari-8.

\section{Conclusions}

We analyzed the June-August 2015 eruption of Mt Raung using high-frequency infrared images obtained using the Himawari-8 AHI. This eruptive sequence was divided into four stages. The Precursory Stage is characterized by the presence of a low-level thermal anomaly in the $2.3 \mu \mathrm{m}$ band, which is considered a preeruption thermal anomaly. Pulse 1 and Pulse 2 were effusive phases comprising high levels of thermal anomalies that formed a consecutive two-pulse pattern in the timeseries variations at $1.6,2.3$ and $3.9 \mu \mathrm{m}$. This pattern is believed to reflect the effusion rate of lava, which is supported by the results of seismic observations. Based on short-term variations, the start of the lava effusion during Pulse 1 occurred at approximately 6:50 UTC on 20 June, whereas the start of lava effusion during Pulse 2 occurred at approximately 20:20 UTC on 1 August. On the last day of Pulse 1, a small thermal pulse was recognized in this 

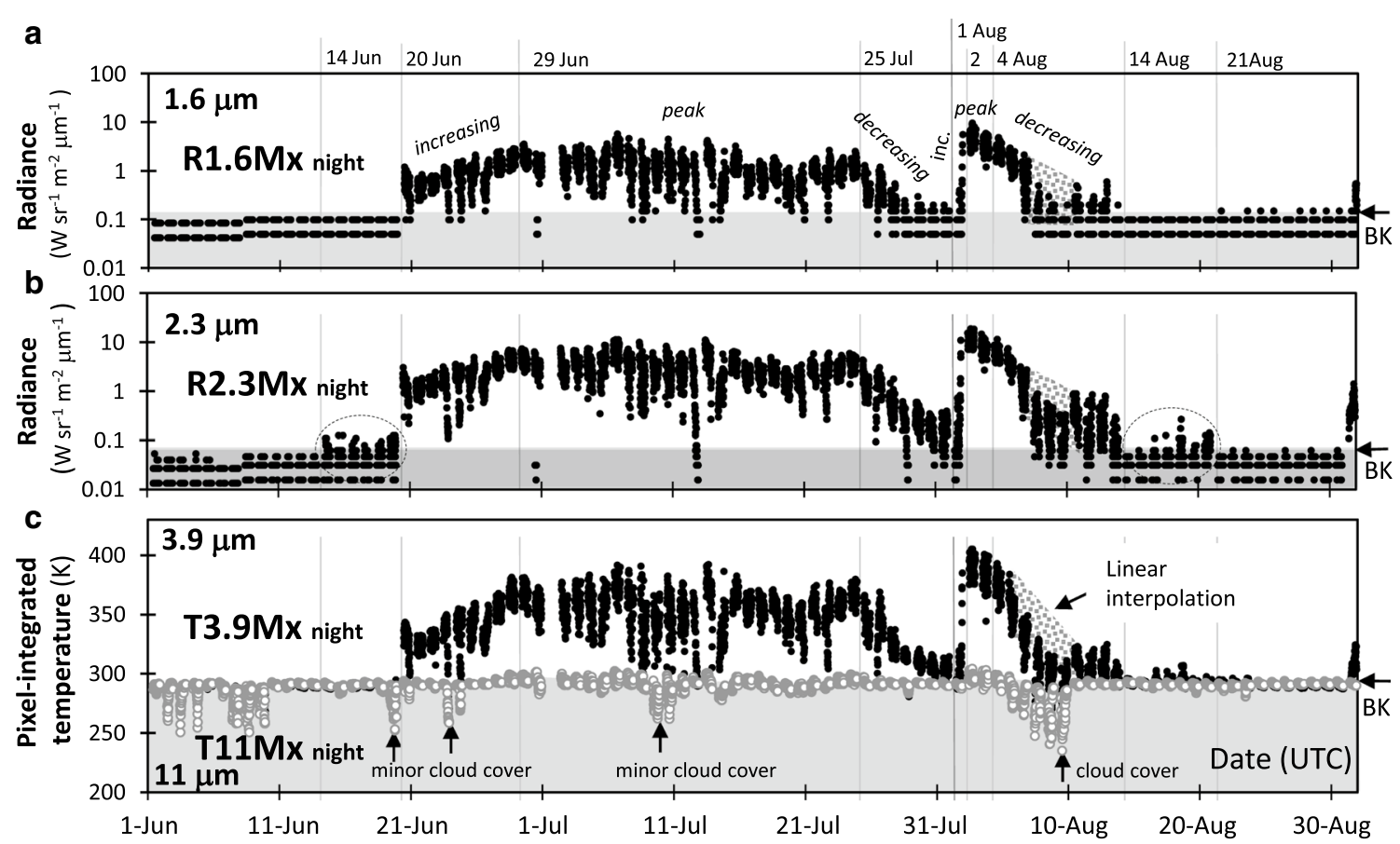

d

\begin{tabular}{|c|c|c|c|c|c|c|}
\hline \multicolumn{3}{|c|}{ Precursory St } & \multicolumn{2}{|l|}{ Pulse 1} & Pulse 2 & \multirow[t]{2}{*}{ Term } \\
\hline Stages & Pc & P1-Inc & P1-Pk & P1-Dec & P2-Dec & \\
\hline
\end{tabular}

e
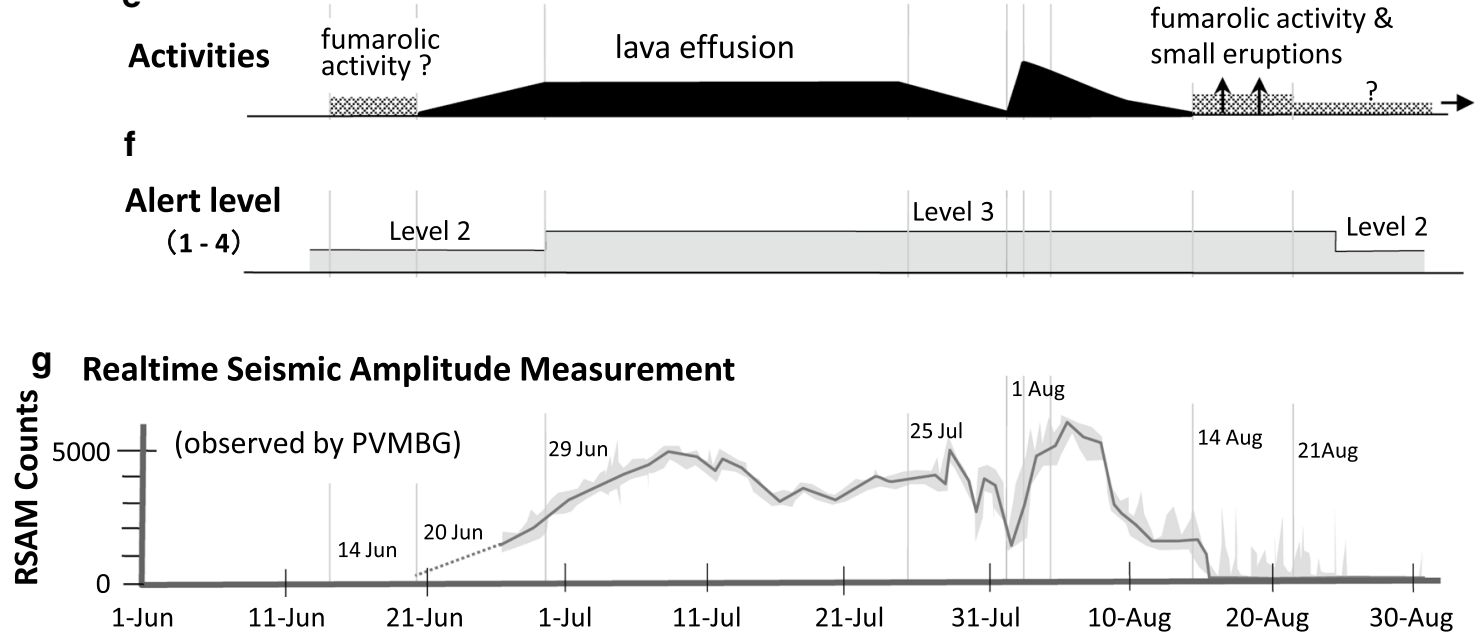

Fig. 4 Results of long-term observations based on nighttime Himawari-8 AHI images, and related information. a Time-series variations in spectral radiance at $1.6 \mu \mathrm{m}(\mathrm{R} 1.6 \mathrm{Mx})$. b Time-series variations in spectral radiance at $2.3 \mu \mathrm{m}(\mathrm{R} 2.3 \mathrm{Mx})$. c Time-series variations in pixel-integrated temperatures at $3.9 \mu \mathrm{m}(\mathrm{T} 3.9 \mathrm{Mx})$ and $11 \mu \mathrm{m}(\mathrm{T} 11 \mathrm{Mx})$. d Stage segmentation based on time-series variations in thermal anomalies. Pc: precursory stage, Tr: terminal stage, P1: pulse 1, P2: pulse 2, Inc: increasing period, Pk: peak period, Dec: decreasing period. e Variations in activity mode. f Alert levels issued by PVMBG. $\mathbf{g}$ Time-series variations in seismic activity (10-min RSAM count) observed by Pusat Vulkanologi dan Mitigasi Bencana Geologi (2016). The original plot has been reproduced and illustrated 

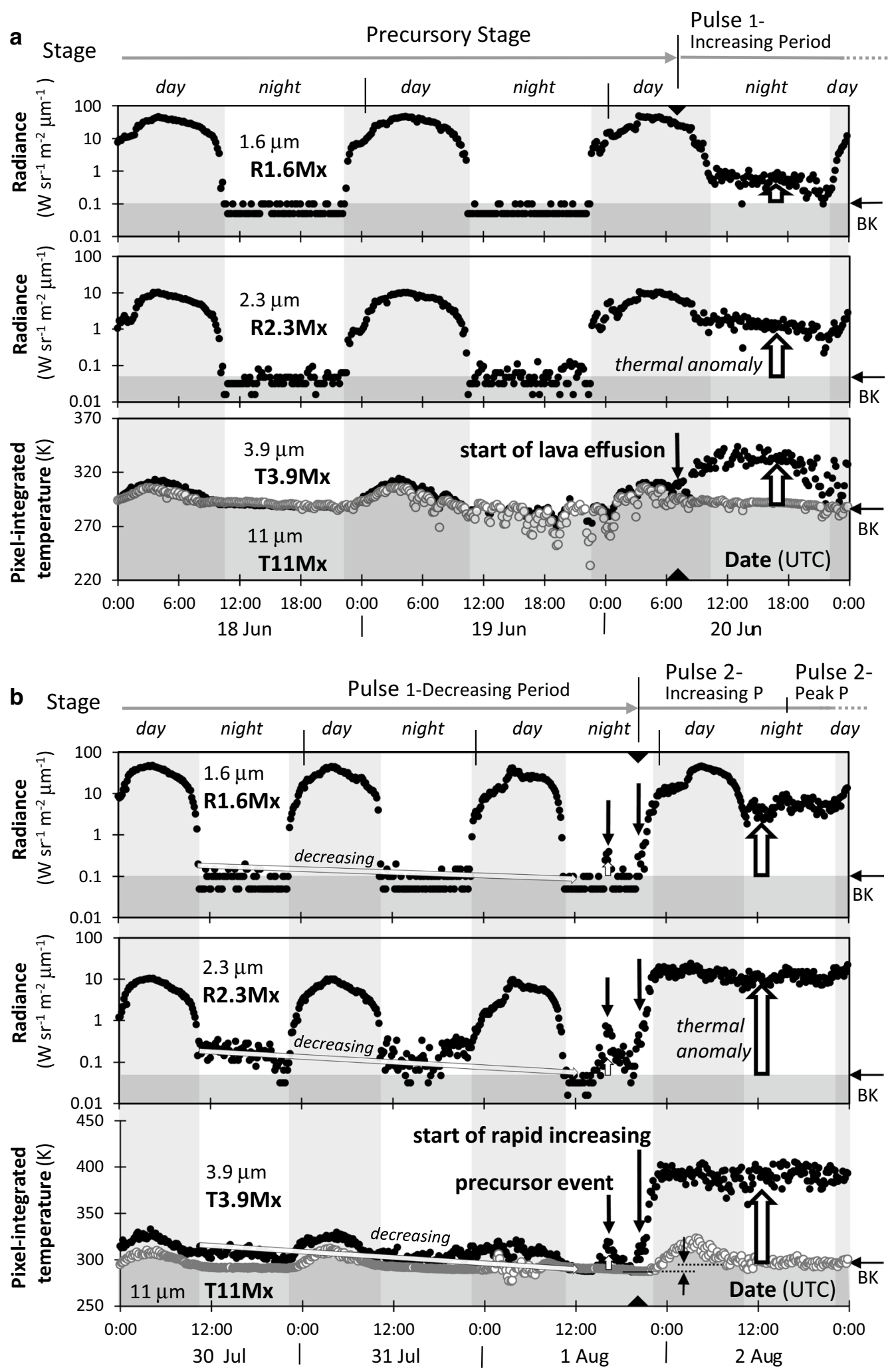

Fig. 5 a Estimated onset time of lava effusion based on short-term variations in R1.6Mx and R2.3Mx and the combined plot of T3.9Mx and T11Mx. Data were not corrected for sunlight effects. $\mathbf{b}$ Estimated time of the reactivation of lava effusion 
variation, which is considered to represent a precursor to the reactivation of lava effusion in Pulse 2. The Terminal Stage is also a stage featuring low-level thermal anomalies that are related to gas emissions. One of the representative eruptive sequences of effusive eruptions involving Strombolian and/or lava fountaining is that the effusion rate of lava undergoes long-term variations in the following pattern: the initial period features a gradual increase, the middle period features a high level of activity with depressions or fluctuations, and the final period features a gradual decrease. Additionally, over shorter timescales, this rate is continuous and changes very gradually. Highfrequency observations obtained using the Himawari- 8 AHI thus have the potential to provide information that is useful for hazard assessment and civil protection purposes, particularly in remote volcanoes.

\section{Authors' contributions}

TK, FM and MW analyzed the volcanic activity and $\mathrm{KT}$ and $\mathrm{AY}$ processed the original Himawari-8 data. All authors read and approved the final manuscript.

\begin{abstract}
Author details
${ }^{1}$ Earthquake Research Institute, The University of Tokyo, 1-1-1 Yayoi, Bunkyo-Ku, Tokyo 113-0032, Japan. ${ }^{2}$ College of Humanities and Sciences, Nihon University, 3-25-40 Sakurajosui, Setagaya-Ku, Tokyo 156-8550, Japan. ${ }^{3}$ Department of Geography, King's College London, Strand, London WC2R 2LS, UK.
\end{abstract}

\begin{abstract}
Acknowledgements
This work was supported by a Grant-in-Aid for Scientific Research (A) from the Japan Society for the Promotion of Science KAKENHI (Grant No. 23241055 to TK), GCOM/RA4 (PI No. 133 to TK) from the Earth Observation Research Center of the Japan Aerospace Exploration Agency (JAXA/EORC) and the Earthquake and Volcano Hazards Observation and Research Program of the Ministry of Education, Culture, Sports, Science and Technology (MEXT) of Japan (No. 1520). The Himawari-8 AHI data used in this research were collected and managed by the NICT Science Cloud led by K. Murata and were originally received by the Meteorological Research Center of the Japan Meteorological Agency. We thank H. Murakami of JAXA/EORC and Y. Honda and K. Kajiwara of Chiba University for helpful suggestions. We are also very grateful to two anonymous reviewers for constructive comments.
\end{abstract}

\section{Competing interests}

The authors declare that they have no competing interests.

\section{Ethics approval and consent to participate} Not applicable.

\section{Publisher's Note}

Springer Nature remains neutral with regard to jurisdictional claims in published maps and institutional affiliations.

Received: 15 February 2018 Accepted: 15 May 2018 Published online: 25 May 2018

\section{References}

Coordination Group for Meteorological Satellite (1999) LRIT/HRIT global specification. http://www.cgms-info.org/documents/pdf_cgms_03.pdf. Accessed 7 May 2018

Dehn J, Dean K, Engle K, Izbekov P (2002) Thermal precursors in satellite images of the 1999 eruption of Shishaldin volcano. Bull Volcanol 64:525-534

Dragoni M (1989) A dynamical model of lava flows cooling by radiation. Bull Volcanol 51:88-95
Endo ET, Murray T (1991) Real-time seismic amplitude measurement (RSAM): a volcano monitoring and prediction tool. Bull Volcanol 53:533-545. https://doi.org/10.1007/BF00298154

Francis PW, Rothery DA (1987) Using the landsat thematic mapper to detect and monitor active volcanoes: an example from Lascar volcano, Northern Chile. Geology 15:614-617

Global Volcanism Program (2015) Smithsonian Institution National Museum of Natural History, global volcanism program, Raung. http://volcano.si.edu/ volcano.cfm?vn=263340. Accessed 7 May 2018

Harris AJL (2013) Thermal remote sensing of active volcanoes, a user's manual. Cambridge University Press, UK

Ishihara K, Iguchi M, Kamo K (1990) Numerical simulation of lava flows on some volcanoes in Japan. In: Fink J (ed) Lava flows and domes. Springer, Berlin

Japan Meteorological Agency (2015a) Himawari-8/9 operational information. http://www.data.jma.go.jp/mscweb/en/operation8/. Accessed 7 May 2018

Japan Meteorological Agency (2015b) Himawari-8/9 Himawari standard data user's guide version 1.2. http://www.data.jma.go.jp/mscweb/en/himaw ari89/space_segment/hsd_sample/HS_D_users_guide_en_v12.pdf. Accepted 7 May 2018

Kagiyama T, Tsuji H (1987) Thermal precursor of the 1986 Izu-Oshima eruption and its present state. Earth Monthly 9:435-440 (in Japanese)

Kaneko T, Takasaki K, Yasuda A, Aoki Y (2006) Thermal surveillance of the Asama 2004-2005 activity using MODIS nighttime infrared images. J Volcanol Soc Jpn 51:273-282 (in Japanese with English abstract)

Maeno F, Nakada S, Kaneko T (2016) Morphological evolution of a new volcanic islet sustained by compound lava flows. Geology. https://doi. org/10.1130/g37461.1

Maeno F, Nakano S, Yoshimoto M, Ohminato T, Watanabe A, Kawakami K, Chida T, Takeo M (2017) First landing and survey of a new volcanic island: Nishinoshima. J Geogr 126(1):N1-N13 (in Japanese)

Neumann van Padang M (1951) Indonesia. Catalog of active volcanoes of the world and solfatara fields. Rome IAVCEI 1:1-271

Newhall CG, Dzurisin D (1988) Historical unrest at large calderas of the world. US Geol Surv Bull 1855

NHK (2015) Birth of the new volcanic isle-unveiling a mystery of creation of the earth—NHK Special. https://www.nhk-ondemand.jp/goods/G2015 064334SA000/?spg=P200800000500000. Accessed 7 May 2018

Oppenheimer C (1991) Lava flow cooling estimated from Landsat Thematic Mapper infrared data: the Lonquimay eruption (Chile, 1989). J Geophys Res 96(B13):21865-21878

Oppenheimer C (1997) Surveillance and mapping of volcanoes and their emissions by satellite remote sensing. Geography 82:317-333

Oppenheimer C, Francis PW, Rothery DA, Carlton RW (1993) Infrared image analysis of volcanic thermal fractures: Lascar volcano, Chile, 1984-1992. J Geophys Res 98(B3):4269-4286

Pfeiffer T (2015) Raung volcano (East Java, Indonesia): photos August 2015. https://www.volcanodiscovery.com/photos/raung/august2015/impre ssions.html. Accessed 7 May 2018

Pusat Vulkanologi dan Mitigasi Bencana Geologi (2016) Evaluasi Tingkat Aktivitas Level li (waspada) G. Raung. http://www.vsi.esdm.go.id/index.php/ gunungapi/aktivitas-gunungapi/1095-evaluasi-tingkat-aktivitas-level -ii-waspada-g-raung. Accessed 7 May 2018

Rothery DA, Francis PW, Wood CA (1988) Volcano monitoring using short wavelength infrared data from satellites. J Geophys Res 93:7993-8008

Wooster MJ, Kaneko T (1998) Satellite thermal analysis of lava dome effusion rate at Unzen volcano, Japan. J Geophys Res 103:20935-20947

Wooster MJ, Rothery DA (1997) Thermal monitoring of Lascar volcano, Chile, using infrared data from the along-track scanning radiometer: a 1992-1995 time series. Bull Volcanol 58:566-579

Yamashita S, Miyamoto K (2009) Basic studies on influence of the slab layer on cooling of lava flows. Abstract of 2009 JSCE annual meeting, CS9-001 (in Japanese)

Yanto A (2015) Mount Raung (Gunung Raung) eruption made volcano cone and fresh lava river. https://www.youtube.com/watch?v=gAnJaa_ZVJA. Accessed 7 May 2018 